\title{
Readiness of SMEs on Digital Payment for Business Sustainbility
}

\author{
Novitasari Agus Saputri \\ Fakultas Ekonomi dan Bisnis, Program Studi Akuntansi, Universitas Muhamamdiyah Malang, Malang, Indonesia \\ Email: novitasariagus@umm.ac.id \\ Email Penulis Korespondensi: novitasariagus@umm.ac.id \\ Submitted: 17/11/2021; Accepted: 26/11/2021; Published: 30/11/2021
}

\begin{abstract}
Abstrak-Penelitian ini bertujuan untuk menganalisis kesiapan UMKM dalam menggunakan digital payment untuk menunjang keberlanjutan usaha jika dilihat tingkat risiko dan manfaat menggunakan digital payment, fasilitas yang dimiliki, kemampuan menggunakan digital payment dan kebutuhan UMKM terhadap digital payment bersamaan dengan berkembangnya teknologi saat ini. Teknik analisis data yang digunakan menggunaan teknik analasis data deskriptif kualitatif dengan tahapan analisis data yaitu tahap dokumentasi data, reduksi data, display data dan menyusun kesimpulan. Hasil penelitian ini menunjukan bahwa secara umum responden yakni pelaku usaha UMKM menjawab sangat setuju menggunakan e-money dalam menjalankan operasional perusahaan. Penggunaan e-money dianggap efektif untuk menunjang kegiatan operasional perusahaan. Adapun selain itu, penggunaan e- money memberikan kegunaan secara keseluruhan. Penggunaan e- money kemungkinan akan menimbulkan risiko bagi penggunanya, baik risiko waktu maupun biaya. Adapun selain risiko yang akan dihadapi, responden memiliki asumsi bahwa penggunaan e- money juga akan menghadapi kerugian. Adapun kerugian ini tidak sebanding dengan manfaat yang akan diterima kedepanya. Hal ini diperkuat dengan penelitian terdahulu yang menyampaikan bahwa bahwa beberapa faktor yang mempengaruhi sesorang mengadopsi teknologi berupa penggunaan uang elektronik yaitu karena keamanan dan kerahasiaan, manfaat kegunaan, kemudahan pengguna, kesenangan, kepercayaan dan risiko. Adapun dengan demikian penggunaan digital payment dianggap mampu menunjang keberlanjutan usaha.
\end{abstract}

Kata Kunci: Kesiapan; UMKM; Digital Payment; Keberlanjutan Usaha

Abstract-This study aims to analyze the readiness of MSMEs in using digital payments to support business sustainability in terms of the level of risks and benefits of using digital payments, the facilities they have, the ability to use digital payments and the needs of MSMEs for digital payments along with the development of current technology. The data analysis technique used was descriptive qualitative data analysis technique with the stages of data analysis, namely the data documentation stage, data reduction, data display and drawing conclusions. The results of this study indicate that in general the respondents, namely MSME business actors, strongly agree to use e-money in carrying out company operations. The use of e-m money is considered effective to support the company's operational activities. Apart from that, the use of e-money provides overall usefulness. The use of e-money is likely to pose risks to its users, both time and cost risks. In addition to the risks to be faced, respondents have the assumption that the use of e-money will also face losses. The losses are not proportional to the benefits to be received in the future. This is reinforced by previous research which stated that several factors that influence someone to adopt technology in the form of using electronic money are security and confidentiality, usability benefits, user convenience, fun, trust and risk. Meanwhile, the use of digital payments is considered capable of supporting business sustainability.

Keywords: Readiness; SME's; Digital Payment; Sustainbility

\section{PENDAHULUAN}

Pandemi COVID-19 memiliki dampak pada segala aspek termasuk dalam aspek ekonomi. Dampak ini dapat menimbulkan terjadinya krisis ekonomi terutama di Indonesia. Ditengah pandemi saat ini banyak sekali Usaha Mikro Kecil dan Menengah (UMKM) yang terkena dampaknya, sehingga menyebabkan omset yang dihasilkan oleh UMKM mengalami penurunan yang sangat signifikan. Tidak hanya itu dengan adanya pandemi ini semua pelaku UMKM juga dituntut untuk dapat memanfaatkan teknologi dalam hal financial technology untuk meningkatkan pendapatan yang dihasilkan. Hal ini sesuai dengan hasil penelitian yang dilakukan oleh Trimulato, 2020 yang menyatakan bahwa fintech syariah dapat menambahkan perananya bagi UMKM tidak hanya sekedar memberikan penyaluran pembiayan akan tetapi juga ikut mendorong perkembangan khususnya dalam hal pemasaran produk- produk yang dihasilkan UMKM. Financial technology juga memberikan pelayanan dengan menyediakan marketplace untuk UMKM serta menjadi katalis tentang produk- produk yang tepat bagi UMKM untuk diproduksi ditengah pandemi. Beriringan dengan marketplace, financial technology juga menyediakan model layanan pembayaran digital payment dengan berbagai produk yang bisa dimanfaatkan oleh konsumen untuk melakukan trnasaksi. Dimana layanan-layanan tersebut dapat memudahkan konsumen dalam melakukan pembayaran dalam setiap transaksi yang dilakukan. Meskipun begitu, masih banyak pelaku UMKM yang masih kesulitan dalam memanfaatkan digital payment tersebut untuk keberlangsungan usaha mereka. Terutama bagi pelaku UMKM yang memiliki tingkat literasi IPTEK yang rendah.

Adapun jika dibandingkan dengan hasil penelitian yang terdahulu sebagai suatu bahan perbandingan dan sebagai acuan, maka hasil penelitian yang dilakukan oleh Restriana Hadi Oktalasa (2019) Dengan judul, "Kesiapan Penggunaan Mobile Payment Gopay Pada Usaha KecilMenengah (UKM) Menggunakan Technology-Organization-Environment (TEO) Framework, yang mana hasil dari penilitian ini yaitu, terkait dengan hasil evaluasi kesiapan pelaku UMKM dalam menggunakan digital payment Gopay dapat dikatakan cukup siap. Sedangkan untuk, hasil penelitian Evi Rosalina Widyayanti (2020) dengan judul, “Analisis Pengaruh Kecenderungan Pergeseran Sistem Pembayaran Dari Tunai ke NonTunai/Online Payment Terhadap Peningkatan Pendapatan Usaha (Studi pada UMKM di Yogyakarta), diperoleh hasil bahwa, presentase penggunaan sistem pembayaran secara online lebih diminati, dan lebih nyaman untuk digunakan. 
Hasil penelitian di atas dikuatkan dengan data hasil penelitian yang dilakukan oleh Evi Rosalina (2020) yaitu pada dasarnya UMKM setuju dan nyaman menggunakan sistem pembayaran non tunai/ online payment, dan menghasilkan kemungkinan benar dalam peningkatan pendapatan usaha. Kesimpulan dari analisa pada penelitian tersebut adalah semua sumber informasi (UMKM) yang mengisi kuisioner dan diwawancarai memberikan jawaban setuju/Ya sebesar $60 \%$ hingga 100\%, artinya bahwa kecenderungan perubahan sistem pembayaran dari tunai ke non tunai dirasakan memberikan pengaruh terhadap peningkatan pendapatan usaha oleh pelaku UMKM di Yogyakarta.

Perkembangan teknologi yang terus berkembang juga terus merubah perilaku masyarakat. Perilaku masyarakat berubah secara tidak langsung menenkankan pada perkembangan teknologi (Dian Dinata Houston, 2019). Secara sadar maupun tidak sadar perubajan perilaku masyarakat karena adanya perkembangan inovasi. Perkembangan teknologi di berbagai sektor akhirnya merubah perilaku model belanja dari model offline menjadi online. Selain itu perubahan model transaksi juga berubah menjadi secara digital atau sering disebut dengan digital payment. Menurut (Katadata.co.id, 2019) terdapat 37 perusahaan payment yang diterbitkan oleh financial technology. Perusahaan mobile payment yang diterbitkan tidak hanya diterbitkan oleh fintech saja akan tetapi juga diterbitkan oleh bank dan perusahaan telekomunikasi.

Contoh mobile payment yang telah berhasil dikembangkan oleh fintech, bank dan perusahaan telekomunikasi adalah seperti Paytren, Ovo, Dana, GoPay, LinkAja, Sakuku, Cashback, dan lain sebagainya. Adapaun dengan adanya perkembangan teknologi yang semakin canggih maka model pembayaran juga semakin mudah dilakukan. Secara sadar maupun tidak sadar masyarakat didesak oleh perkembangan teknologi untuk berupaya cashless.

Katadata.co.id (2019) juga menyatakan bahwa sejumlah 38 dompet digital sudah berlisensi resmi. Hasil penelitian dari iPrice menyebutkan bahwa Gojek sebagai dompet digital dengan pengguna aktif bulanan terbesar di Indonesia sejak kuartal IV di tahun 2017. Peringkat kedua yaitu Ovo yang bertahan selama empaat tahun berturut- turut. LinkAja merupakan hasil perubahan dari T-cash dari produk Telkomsel. Pada kuartal II tahun 2019 LinkAja bergeser posisi turun menjadi peringkat empat, digeser oleh Dana. Kemudian pada peringkat kelima muncul Jenius. Beberapa model pembayaran digital tersebut saat ini sedang banyak digunakan dan diminati konsumen sebagai model pembayaran digital yang sangat mudah, efisien dan aman.

Adapun data diatas menunjukan bahwa penggunaan digital payment sudah mendominasi kaum generasi X. Y, dan Z. Transaksi menggunakan digital dianggap lebih mudah dan praktis selain itu juga memberikan benefit lain dari pengguhaan transaksi melalui digital payment dan fintech yaitu adanya promosi- promosi yang didapatkan seperti cashback dan diskon. Pembayaran digital sendiri merupakan pembayaran yang dilakukan secara elektronik. Adapun dalam pembayaran elektronik uang uang disimpan, diproses dan diterima dalam bentuk informasi digital dan proses pemindahanya di inisialisasi melalui alat pembayaran elektronik. Pembayaran secara tradisional dilakukan dengan menggunakan uang tunai, cek atau kartu kredit sedangkan pembayaran elektronik dilakukan menggunakan software tertentu, kartu pembayaran dan uang elektronik (Trihasta dan Fajaryanti, 2008)

Tujuan penelitian ini adalah untuk menganalisis kesiapan UMKM dalam menggunakan digital payment untuk menunjang keberlanjutan usaha jika dilihat tingkat risiko dan manfaat menggunakan digital payment, fasilitas yang dimiliki, kemampuan menggunakan dan kebutuhan UMKM terhadap digital payment bersamaan dengan berkembangnya teknologi saat ini.

\section{METODE PENELITIAN}

\subsection{Kerangka Dasar Penelitian}

Jenis penelitian ini adalah penelitian deskriptif kualitatif. Penelitian deskriptif karena bertujuan untuk menjelaskan bagaimana kesiapan UMKM dalam menghadapi era digital seperti saat ini khususnya dalam hal pembayaran digital. Adapun jenis penelitian kuantitatif karena menganalisis kesiapan UMKM dalam hal penyesuaian diri untuk menggunakan pembayarandigital.

\subsection{Populasi Dan Teknik Penentuan Sampel}

Populasi dari penelitian ini adalah seluruh UMKM yang ada di seluruh Kota Malang yang berjumlah kurang lebih 128.988 UMKM (BPS, 2020). Penelitian ini menggunakan penelitian sampel. Sampel penelitian menggunakan purposive sampling, artinya ada beberapa kriteria pengambilan sampel penelitian. Kriteria pengambilan sampel diantaranya adalah sebagai berikut:

a. UMKM yang berskala Menengah

b. Usaha menengah yang bergerak dibidang perdagangan. Hal ini mengingat usaha perdagangan memiliki intensitas transaksi yang lebih banyak dibanding usaha jasa dan manufaktur

\subsection{Definisi Operasional dan Pengukuran Variabel}

UMKM merupakan usaha produktif yang dimiliki perorangan maupun badan usaha yang telah memenuhi kriteria dalam setiap jenis usahanya. Adapun melihat kebermanfaatan penelitian ini maka usaha perseorangan maupun badan usaha yang dimaksud alah usaha kecil yang memiliki omzet tahuanan mencapai Rp 300.000.000,00 dan usaha menengah yang memiliki omzet tahuan mencapai Rp 2.500.000.000,-

Kesiapan UMKM dilihat dari suatu kondisi di mana seseorang bersedia, siap dan dapat melaksanakan sesuatu untuk mencapai sebuah tujuan tertentu. Kondisi seseorang tersebut juga mempengaruhi hasil dari tujuan yang diinginkan 
tersebut. Kondisi seseorang tersebut dapatdianalisis melalui kondisi fisikyang terdiri dari fasilitas (alat), kebutuhan atau motif, risiko dan manfaat serta pengalaman yang telah dilalui.

\subsection{Jenis dan Sumber Data}

Jenis data yang digunakan dalam penelitian ini adalah data primer yang diperoleh langsung dari sumbernya, yaitu pelaku UMKM baik yang sudah menggunakan digital payment maupun yang belum menggunakan digital payment.

\subsection{Teknik Perolehan Data}

Teknik perolehan data yang digukana dalam penelitian ini adalah dengan menyebar kuesioner kepada responden yakni pelaku UMKM UMKM baik yang sudah menggunakan digital payment maupun yang belum menggunakan digital payment. Selain menyebar kuesioner, penelitijuga melakukan wawancara langsung bersama pelaku UMKM. Kuesioner yang akan digunkan dalam penelitian ini menggukan pengukuran skala likert sedangkan wawancara yang akan dilakukan kepada responden merupakan wawancara terbuka.

\subsection{Teknik Analisis Data}

Penelitian ini mengunakan analisis deskriptif kuantitatif dan kualitatif. Berdasarkan data yang diperoleh peneliti berupaya menggambarkan secara sistematis, akurat dan faktual mengenai hal-hal yang berkaitan dengan lapangan sebagai fakta , sifat-sifat dan hubungan antar fenomena. Teknik kuantitatif juga akan menggunakan analisis frekuensi yang bertujuan untuk memberikan gambaran mengenai kondisi secara umum.

Miles dan Haberman, menjelaskan bahwa ada beberapa tahap yang dapat dilakukan dalam proses teknik analisis data. Teknik analisis data yang dimaksud melalui tahap dokumentasi, reduksi data, display data dan menyusun kesimpulan. Dokumentasi data dilakukan dengan cara melakukan wawancara kepada subjek penelitian. Selain melakukan wawancara, peneliti juga menyebar kuesioner untuk menghimpun informasi tentang efektifitas penggunaan e-money (Miles and Haberman,2014).

Reduksi data merupakan tehnik analisis data kualitatif untuk menyederhanakan dan menggolongkan data yang diperlukan dalam penelitian. Dalam hal ini peneliti mengidentifikasi subjek penelitian yang berhasil di wawancarai dan yang telah mengisi kuesioner. Data tersebut dikelompokan dan dijabarkan berdasarkan kondisi yang sebenarnya. Mendisplay data merupakan menyususn sekumpulan data dengan disusun secara sistematis agar lebih mudah dipahami sehingga memberikan kemungkinan hasil kesimpulan. Kesimpulan dan verifikasi merupakan tahap terakhir dari tehnik analisi data deskriptif kualitatif untuk menarik kesimpulan dalam mencari hubungan, persamaan dan perbedaan sehingga penulis dapat menarik sebuah kesimpulan.

\section{HASIL DAN PEMBAHASAN}

Penyebaran keusioner dilakukan melalui google form yang dibagikan kepada responden. Responden adalah pelaku UMKM yang menggunakan e-money berupa ovo dan go pay. Deskripsi responden yang menyerahkan kuesioner sebanyak 52 responden. Responden yang telah mengisi merupakan 41 responden perempuan dan 11 responden laki- laki. Usia responden kisaran 17 - 54 tahun dengan tingkat pendidikan SLTA/sederajat - sarjana berjumlah 47 dan 5 tidak menjawab. Jenis usaha yang dijalankan berupa 6 usaha manufaktur, 2 usaha jasa dan 44 usaha dagang. Omzet responden yang mengisi google form beragam, yakni 1 memiliki omzet $<10$ juta, 38 memiliki omzet $<$ Rp 50.000.000,-, 9 memiliki omzet Rp 50 juta - 100 juta dan 3 responden memiliki omzet $>$ Rp 200 Juta.

Hasil peneyebaran kuesioner berdasarkan indikator manfaat, risiko dan kemudahan dapat dilihat melalui tabel berikut ini:

Tabel 1. Hasil penyebaran kuesioner

\begin{tabular}{|c|c|c|c|c|c|}
\hline \multirow[t]{2}{*}{ Indikator } & \multicolumn{5}{|c|}{ Skala } \\
\hline & 1 (STS) & $2(\mathrm{TS})$ & 3 (Netral) & $4(\mathrm{~S})$ & 5 (SSS) \\
\hline Manfaat: & & & & & \\
\hline Produktifitas & & & 4 & 15 & 33 \\
\hline Efektivitas & & & 3 & 10 & 39 \\
\hline Kepentingan & & 2 & 3 & 7 & 42 \\
\hline Kegunaansecara keseluruhan & & & 3 & 8 & 31 \\
\hline Kemudahan: & & & & & \\
\hline Mudah dipelajari & & & & & 36 \\
\hline Fleksibel & & & & & 42 \\
\hline Mudah dikontrol & & & & & 36 \\
\hline Mudah digunakan & & & & & 39 \\
\hline Total & & 2 & 13 & 40 & 298 \\
\hline
\end{tabular}

Sumber : Data diolah oleh peneliti (2021) 
Berdasarkan hasil penyebaran keusioner kepada responden, 33 responden mengemukakan bahwa 33 atau setara dengan 63,46\% responden menjawab sangat setuju sekali bahwa menggunakan e money dapat menigkatkan produktifitas, 39 atau setara $75 \%$ responden menjawab penggunaan e money lebih efektif, $80.07 \%$ menjawab e money memiliki kepentingan dalam menggunakan e money dan juga 59,6\% atau 31 responen menjawab e money memberikan kegunaan secara keseluruhan bagi penggunanya. Hal ini diperkuat hasil wawancara yang dilakukan kepada responden yang bernama Aisyah Nabilah pelaku usaha dagang dnegan omzet 60 - 80 juta per tahun. Aisyah menjawab "dengan menggunakan emoney saya bisa bertransaksi dengan mudah. Di masa pandemi seperti saat ini saya berbelanja bahan dari rumah. Terlebih lagi saya bisa membeli kain dari Bandung dengan menggunakan pembayaran transfer. Saya membeli kain di Bandung karena harganya jauh lebih murah dari pada di Kota Malang. Dengan adanya kemudahan bertransaksi saya bisa mendapatkan bahan dengan harga murah sehingga dapat harga bersaing dengan olshop lainnya". Hasil penelitian ini diperkuat dengan teori TAM yang menyebutkan bahwa penggunaan teknologi akan memberikan manfaat lebih bagi penggunanya. Hal tersebut juga selaras dengan hasil penelitian yang dilakukan oleh Hendra (2018) yang mengemukaakn bahwa penggunaan teknologi memberikan manfaat dan tidak akan membutuhkan waktu yang lama bagi pengunanya sehingga penggunaan teknologi memiliki banyak waktu untuk mengerjakan pekerjaan lain dengan demikian terjadi efektifitas kinerja.

Adapun hasil kuesioner mengenai indikator kemudahan, responden menjawab 69,2\% atau 36 responden sangat setuju sekali e money mudah dipelajari. 42 responden atau setara 80,7\% responden lebih fleksibel saat menggunakan e money dalam bertransaksi. Selanjutnya responden juga merasa penggunaan e money mudah dikontrol dan digunakan, masing- masing menjawab $69,2 \%$ dan $71,2 \%$ responden. Hasil penelitian ini diperkuat dengan hasil wawancara yang dilakukan oleh peneliti. Responden yang di wawancarai adalah Astrid pemilik olshop dengan amzet kurang lebih 115 juta pertahun, mengemukakan bahwa "saat menggunakan e money transaksi lebih mudah. Cukup menggunakan smart phone seтиа aktifitas transaksi baik jual maupun beli dapat dilakukan. Hanya saja kelemahanya adalah terkadang jaringan trouble atau di wilayah tertentu sinyal sulit didapatkan. Akan tetapi jika dilihat dari manfaat penggunaan e money sangat bermanfaat". Hasil penelitian ini sejalan dengan hasil penelitian terdahulu yang dilakukan oleh Isharijadi, dan Elana Era Yusdita (2021) yang menyebutkan bahwa penggunaan e money memberikan kemudahan baik pada saat transaksi maupun perhitungan yang dilakukan secara automatisasi sehingga pengguna tidak perlu lagi melakukan perhitungan. Adapun perhitungan yang dilakukan oleh pelaku usahaa hanya sebagai kontrol. Hal tersebut juga diperkuat denga teori TAM (Technology Acceptance Model)yang dikemukakan oleh Davis (1989) yang mengemukakan bahwa dasar seseorang menggunakan dan menerima teknologi adalah karena persepsi kemudahan dan manfaat sehingga pekerjaan lebih efektif dan efisien.

Indikator pengukuran tentang risiko penggunaan e money menunjukan bahwa risiko menggunakan e money kemungkinan akan berisiko bagi pengguna baik waktu dan biaya sebesar $75 \%$ atau setara 39 responden menjawab sangat setuju sekali kedepan pengguna e money akan menerima risiko. Akan tetapi sebesar 31 respomden atau setara dengan 59,6\% responden berpikir bahwa penggunaan e money akan menerima kerugian. Prosentase tersebut lebih kecil jika dibandingkan dengan manfaat dan kemudahan yang diterima oleh pengguna emoney. Hasil penelitian ini dikuatkan oleh hasil peneltian terdaahulu yang dilakukan oleh Purwati (2013) yang menunjukan bahwa beberapa faktor yang mempengaruhi sesorang mengadopsi teknologi berupa penggunaan uang elektronik yaitu karena keamanan dan kerahasiaan, manfaat kegunaan, kemudahan pengguna, kesenangan, kepercayaan dan risiko. Hasil wawancara pada pelaku UMKM pengguna e money juga menyampaikan bahwa "Menurut saya E-money tidak dapat meminimalisir human error. Karena kesalahan bisa terjadi kapan saja, baik transaksi offline maupun online. Saya sangat sering salah transfer, karena daftar nama rekening yang ada pada m banking BCA saya sering sama. Misal nama Fatimah terdapat beberapa orang, apalagi jika namanya hanya Fatimah saja. Saya pun jadi harus meneliti kembali berapa angka terakhir nomor rekeningnya. E Money memberikan kemudahan waktu dan lebih praktis namun tidak dapat mengantisipasi human error" Hal tersebut dikemukakan oleh Aisyah Nabiah pelaku usaha UMKM yang menggunakan e money.

\section{KESIMPULAN}

Penggunaan e-money dianggap efektif untuk menunjang kegiatan operasional perusahaan. Adapun selain itu, penggunaan e- money memberikan kegunaan secara keseluruhan. Penggunaan e- money kemungkinan akan menimbulkan risiko bagi penggunanya, baik risiko waktu maupun biaya. Adapun selain risiko yang akan dihadapi, responden memiliki asumsi bahwa penggunaan e- money juga akan menghadapi kerugian. Adapun kerugian ini tidak sebanding dengan manfaat yang akan diterima kedepanya. Hal ini diperkuat dengan penelitian terdahulu yang menyampaikan bahwa bahwa beberapa faktor yang mempengaruhi sesorang mengadopsi teknologi berupa penggunaan uang elektronik yaitu karena keamanan dan kerahasiaan, manfaat kegunaan, kemudahan pengguna, kesenangan, kepercayaan dan risiko. Adapun dengan demikian penggunaan digital payment dianggap mampu menunjang keberlanjutan usaha.

\section{UCAPAN TERIMAKASIH}

Terima kasih disampaikan kepada pihak-pihak yang telah mendukung terlaksananya penelitian ini. 


\section{REFERENCES}

Ashghar, S. A., \& Nurlatifah, H. (2020). Analisis Pengaruh Perceived Ease of Use, Perceived Usefulness, dan Perceived Risk terhadap Keinginan Membeli Kembali melalui e-Trust dan s- Satisfaction (Studi Kasus Pengguna Gopay pada Transaksi UMKM). Jurnal Al Azhar Indonesia Seri Ilmu Sosial, 1(1), 40-52.

Eszi, I. M. (2020). Pengaruh Kesiapan Teknologi Individu terhadap Minat Mahasiswa pada Penggunaan E-Wallet Model Kombinasi Tri dan Tam.

Houston, D. D. (2019). Adopsi Penerimaan Digital Payment Pada Kalangan Milenial. Medium: Jurnal Ilmiah Fakultas Ilmu Komunikasi, 7(2), 55-67.

Kotler, P. (2007).Manajemen Pemasaran. Jakarta : PT Indeks Kelompok Gramedia

https://databoks.katadata.co.id/datapublish/2019/08/23/inilahdaftar-dompet-digital-terbesar-di-indonesia

Katadata.co.id (12 Agustus 2019, Daftar Dompet Digital Terbesar di Indonesia. Diakses pada (8 April 2021)

Nugroho, A., (2018) Regulasi Terkait Pembayaran Elektronik Di Indonesia. 6-7

Oktalasa, R. H. Kesiapan penggunaan mobile payment gopay pada Usaha Kecil Menengah(UKM) menggunakan TechnologyOrganization-Environment (TOE) framework (Bachelor's thesis, Fakultas Sains dan Teknologi Universitas Islam Negeri Syarif Hidayatullah Jakarta).

Primasari, N. S., \& Ghofirin, M. (2021). Sosialisasi Kesiapan Masyarakat Menuju Transaksi Digital di Era New Normal Life. Jurnal Altifani Penelitian Dan Pengabdian Kepada Masyarakat, 1(1), 1-9.

Trihasta, D. (2008, August). "E-payment” SISTEM. In Proceeding, Seminar Ilmiah Nasional Komputer dan Sistem Intelijen (KOMMIT 2008) Auditorium Universitas Gunadarma, Depok, 20-21 Agustus 2008.

Trihasta, D., \& Fajaryanti, J.(2008) “E-Payment” SISTEM. 616

Prisgunanto, I. (2014). Komunikasi Pemasaran Era Digital. Jakarta : CV.Prisani Cendekia

Trimulato, T. (2020). Pengembangan UMKM Melalui Fintech Syariah di Tengah Wabah Covid-19. AL IQTISHADIYAH JURNAL EKONOMI SYARIAH DAN HUKUM EKONOMI SYARIAH, 6(2), 64-85.

Wardani, A. $\quad$ P. $\quad$ Y. $\quad$ K. (2020). PERAN FINANCIAL TECHNOLOGY PADA UMKM: "PENINGKATAN LITERASI KEUANGAN BERBASIS PAYMENT GATEWAY"(Studi Empiris Pada UMKM Kecamatan Buleleng) (Doctoral dissertation, Universitas Pendidikan Ganesha).

Widyayanti, Evi Rosalina (2020) ANALISIS PENGARUH KECENDERUNGAN PERGESERAN SISTEM PEMBAYARAN DARI TUNAI KE NON-TUNAI/ONLINE PAYMENT TERHADAP PENINGKATAN PENDAPATAN USAHA (Studi pada UMKM di Yogyakarta). In: Seminar Nasional dan Call For Paper 2020 : "Paradigma Pengembangan Ekonomi Kreatif di Era 4.0". STIE Widya Wiwaha, Yogyakarta, pp. 187-200. ISBN 978-602-51174-9-7 